\title{
Interactive comment on "Direct dating of overprinting fluid systems in the Martabe epithermal gold deposit using highly retentive alunite" by Jack Muston et al.
}

\section{Anonymous Referee \#1}

Received and published: 14 January 2021

Muston et al present 40Ar/39Ar results from alunite in ten samples from the Martabe gold deposit. They also obtained closure temperature constraints from the alunite which ranged from 390-519C. Based on their results and interpretations, they claim that the gold deposits were formed in 5 discrete growth events. Overall, the text is well written, but it does read like a 40Ar/39Ar textbook in several places. The figures are clear.

The major flaw of this manuscript is that the authors have overinterpreted the age spectra that have been generated and thus one section (section 3.3), two figures (Figures 4 and 6 ), and the conclusions of the paper (5 discrete pulse events) are not supported by 
these data. As noted by the authors, the age spectrum from almost all of the samples are complicated. Numerous criteria have been put forth over the last several decades to evaluate age spectra and to calculate a plateau ages (e.g., Fleck et al., 1977; Sharp and Renne, 2005; Jourdan et al., 2004). In a recent paper consisting of forty $40 \mathrm{Ar} / 39 \mathrm{Ar}$ specialists from around the globe, the following criteria were put forth for a plateau: (1) consist of at least five or more consecutive steps that comprise at least $>50 \%$ of the 39Ar released; (2) not have a slope (i.e., the majority of consecutive plateau steps do not have ascending or descending ages; Sharp and Renne, 2005); and (3) have an isochron regressed through all of the plateau steps with a $(40 \mathrm{Ar} / 36 \mathrm{Ar}) \mathrm{i}$ that is indistinguishable from the atmospheric value at the 95\% confidence level. Almost all of the Muston et al spectra have a significant slope. Only one sample (D3035222) has a plateau based on the Schaen et al (2020) criteria. Moreover, there are no accompanying isochrons with the spectra so the 40Ar/36Ar intercepts cannot be evaluated. Muston et al have selected random concordant steps in many samples to be "plateaus". This is gross overinterpretation. There is not strong evidence for 5 pulses of mineralization and there is no evidence to support the claim that these new data extend the range of alteration beyond what was defined by Sutopo (2013) from 3.3 to 2.0 Ma. The authors claim that the complicated spectra involve mixing between radiogenic argon released from alunite grown at different times based on the method of 'asymptotes and limits' (Forster and Lister, 2004). There is simply not enough data to support this claim. In sum, this manuscript has major flaws and does not warrant publication in GChron in its current form.

Other editorial and interpretive comments: Figure 1: caption says there are 10 samples. Only 9 are shown. Purnama P-1 needs to be added to this figure as it is in figure 6.

Lines 46-47: The host rocks are a series.... The text lists several kinds of hosts

Lines 80-84: The furnace experiments were done so that the diffusion experiments could be done simultaneously. This is the advantage of the furnace analyses compared

Interactive comment 
to a laser unless a laser is equipped with a calibrated optical pyrometer. However, on line 81, the authors claim that furnace experiments have a "major advantage" over laser experiments in that they can produce age spectra with sufficient detail. This statement is misleading and needs to be omitted. Laser analyses of WAY less material than what was used here would also yield age spectra with sufficient detail (see Pan et al., 2019 Economic Geology or Holm et al 2019).

Line 84: the extensive cleaning should minimize the effect of contaminants. Text says maximize.

Line 85: the text is written as if they have used a novel furnace technique. People have been dropping samples into a furnace and degassing them prior to 40Ar/39Ar incremental heating experiments since the 1970's. See Staudacher et al 1978 or McDougall and Harrison, 1988. The text repeatedly states how they did detailed furnace incremental heating experiments in many small steps. However, it doesn't say how the furnace blanks were done. Were they also done in many small increments or did they do a few and interpolate in between furnace blank temperatures? Almost all of these experiments yielded spectra with a similar shape which points towards the spectra being a function of the experiments and not the samples all behaving the same way. Note that the shape of their alunite spectra look very different than the relatively flat spectra generated in a recent study of alunite and jarosite by Ren and Vasconcelos (2019).

Line 121: the authors keep using the word contaminants. The older apparent ages at the beginning of the experiments are stated to be "evidence of contamination." More descriptive detail is needed. The older ages could be due to low temperature excess Ar or it could be attributed to 39Ar recoil (see Jourdan and Renne, 2013). They also say that the steps at the end of the experiment are due to contamination. This could also be due to recoil. Given that Muston et al did not evaluate 39Ar recoil, it should be listed as a possibility in both cases. Accompanying $\mathrm{K} / \mathrm{Ca}$ or $\mathrm{K} / \mathrm{Cl}$ plots should be included so that one could evaluate how these variables evolve as the apparent ages change in the samples. 
Interactive comment on Geochronology Discuss., https://doi.org/10.5194/gchron-2020-41, 2020.

\section{GChronD}

Interactive comment 